\title{
Role of etravirine in the management of treatment-experienced patients with human immunodeficiency virus type I
}

REVIEW

\author{
Rolando MViani \\ Department of Pediatrics, Division \\ of Infectious Diseases, Center \\ for AIDS Research, University of \\ California San Diego School of \\ Medicine and UCSD, Mother, Child \\ and Adolescent HIV Program, Rady \\ Children's Hospital, San Diego, \\ California, USA
}

This article was published in the following Dove Press journal:

HIVIAIDS - Research and Palliative Care

24 June 2010

Number of times this article has been viewed

\begin{abstract}
Etravirine is an oral diarylpyrimidine compound, a second-generation human immunodeficiency virus type 1 (HIV-1) non-nucleoside reverse transcriptase inhibitor (NNRTI) with expanded antiviral activity against NNRTI-resistant HIV-1, to be used in combination therapy for treatment-experienced patients. Compared with first-generation NNRTIs, etravirine has a high genetic barrier to resistance, and is better tolerated without the neuropsychiatric and hepatic side effects of efavirenz and nevirapine, respectively. Its safety profile is comparable to placebo with the exception of rash, which has been mild and self-limited in the great majority of patients. In phase III clinical trials among treatment-experienced patients harboring NNRTIresistant HIV-1, etravirine in combination with an optimized background regimen (OBR) that included ritonavir-boosted darunavir demonstrated superior antiviral activity than the control OBR. In addition, patients on the etravirine arm had fewer AIDS-defining conditions, hospitalizations, and lower mortality compared with the OBR control arm.
\end{abstract}

Keywords: HIV, antiretroviral therapy, non-nucleoside reverse transcriptase inhibitor

\section{Introduction}

Over the last 14 years, combination antiretroviral therapy has led to adequate suppression of human immunodeficiency virus (HIV) replication, immunologic recovery, and a dramatic decline in morbidity and mortality among HIV-infected individuals in the industrialized world, and to a lesser degree in developing countries. ${ }^{1-5}$ The goal of antiretroviral therapy is to suppress HIV replication to undetectable levels. The International AIDS Society-USA Panel currently recommends the combination of 2 reverse transcriptase inhibitors and either the non-nucleoside reverse transcriptase inhibitor (NNRTI) or the ritonavir-boosted protease inhibitor (PI) as the initial therapy. ${ }^{6}$ However, virologic suppression is not always achieved or maintained due to a variety of reasons, such as poor tolerability due to side effects leading to poor compliance, drug-to-drug interactions, and HIV drug resistance. Over the last few years, the use of an NNRTI, such as efavirenz in industrialized countries and nevirapine in resourcelimited settings, had been preferred for first-line treatment due to its high potency and low pill burden. ${ }^{6}$ However, efavirenz and nevirapine have a low genetic barrier to resistance, so that a single amino acid substitution in the viral reverse transcriptase (RT), such as K103N, leads to profound reduction in viral susceptibility to both drugs, conferring class-wide drug resistance. ${ }^{7}$ Transmitted NNRTI drug resistance has been increasing in adolescents and young adults in industrialized countries. ${ }^{8-10}$ Additionally, transmitted NNRTI drug resistance, in particular the mutation in position K103N, has been shown to persist several years in the absence of drug pressure. ${ }^{11}$ In developing 
countries where single-dose nevirapine is being used to prevent mother-to-child HIV transmission, the prevalence of nevirapine drug resistance has been as high as 35\% and $52 \%$ among women and infants exposed to single-dose nevirapine, respectively. ${ }^{12}$

Etravirine (Intelence ${ }^{\circledR}$; Tibotec Therapeutics, Raritan, New Jersey), formerly known as TMC125, is a secondgeneration NNRTI that was approved by the US Food and Drug Administration (FDA) in January 2008 for use in HIV-1-infected individuals at a dose of $200 \mathrm{mg}$ (two 100-mg tablets) twice a day. Its indication is for treatment-experienced adults with evidence of NNRTI drug resistance. ${ }^{13}$ Etravirine is a diarylpyrimidine compound that emerged after a long parallel screening process, involving testing candidate compounds from a series of diarylpyrimidines against wild-type and selected single- and double-mutant, NNRTI-resistant HIV-1 isolates. ${ }^{14}$ Etravirine is highly active against wild-type HIV-1 with a 50\% effective concentration $\left(\mathrm{EC}_{50}\right)$ of $1.4-4.8 \mathrm{nM}$ and shows some activity against HIV-2 with an $\mathrm{EC}_{50}$ of $3.5 \mu \mathrm{M}$. In addition, etravirine retained activity with an $\mathrm{EC}_{50}<100 \mathrm{nM}$ against $97 \%$ of 1,081 clinically derived recombinant viruses resistant to at least one of the first-generation NNRTIs. ${ }^{14,15}$ Etravirine has a diarylpyrimidine-based structure with molecular flexibility that allows it to accommodate to mutational changes in the RT binding pocket. ${ }^{16}$ The NNRTI binding sites are located in codons 100 to 110 and 180 to 190 . The presence of the K103N and Y181C mutations reduces the NNRTI binding affinity, leading to drug resistance. ${ }^{17}$ Etravirine has a higher genetic barrier to HIV drug resistance, with activity against efavirenz- and nevirapine-resistant HIV-1 isolates harboring the $\mathrm{K} 103 \mathrm{~N}$ and $\mathrm{Y} 181 \mathrm{C}$ mutations. ${ }^{14}$ Etravirine, as other NNRTI, is a noncompetitive inhibitor of the HIV RT enzyme; by binding to the hydrophobic pocket proximal to the active site, it causes a conformational change in the enzyme and disrupts its function. ${ }^{16}$ Etravirine has an ability to bind to the RT enzyme even in the presence of such mutations. Its structure allows etravirine to bind to the enzyme in several modes due to the conformational adaptation based on changes in the binding pocket. ${ }^{16}$ The torsional flexibility allows etravirine to reorient itself and bind to the enzyme despite the presence of NNRTI resistance mutations. ${ }^{18}$

\section{Pharmacology Pharmacokinetics}

Early phase I/II studies were conducted with a polyethylene glycol (PEG) capsule formulation (PEG4000) with low bioavailability and high pill burden, needing $900 \mathrm{mg}$ twice a day to provide reliable pharmacokinetic profile. ${ }^{19}$ The PEG formulation resulted in a high incidence of gastrointestinal side effects. ${ }^{20} \mathrm{~A}$ dose-finding, phase II, randomized clinical trial (TMC125-C223) comparing 2 doses of the TF035 formulation (granular layered) of etravirine at 400 or $800 \mathrm{mg}$ twice a day in addition to 2 or more approved antiretroviral agents selected the $800 \mathrm{mg}$ twice a day for further development. ${ }^{21} \mathrm{~A}$ solid dispersion formulation using spray-drying technology was developed to improve etravirine bioavailability and reduce pill burden. A multiple-dose bioavailability study in HIV-infected individuals demonstrated similar steady-state pharmacokinetic exposure for the solid dispersion formulation at a dose of $200 \mathrm{mg}$ twice a day compared with the $800 \mathrm{mg}$ twice a day of the granular-layered formulation with reduced interpatient variability. ${ }^{22}$

Etravirine is currently formulated as a 100-mg tablet that has a more reliable pharmacokinetic profile without the frequent gastrointestinal side effects associated with the PEG capsule formulation. The dose approved by the FDA is $200 \mathrm{mg}$ twice a day. When etravirine is administered under fasting conditions, the systemic exposure is decreased by $50 \%$; therefore, etravirine should be administered after meals. ${ }^{23}$ In patients who have trouble swallowing tablets, the 100-mg tablet can be dispersed in water with comparable bioavailability to the swallowed tablet. ${ }^{23,24}$

Population pharmacokinetic analysis of pooled data from DUET-1 and DUET-2 among 574 patients revealed an etravirine mean (SD) $\mathrm{AUC}_{12 \mathrm{~h}}$ and $\mathrm{C}_{\text {min }}$ of 5,501 $(4,544) \mathrm{ng} \cdot \mathrm{h} / \mathrm{mL}$ and 393 (378) ng/mL, respectively. ${ }^{25}$ In addition, the pooled analysis revealed a mean (SD) $\mathrm{C}_{\max }$ of 797 (668) $\mathrm{ng} / \mathrm{mL}$ at week 24. Clearance $(\mathrm{CL} / \mathrm{F})$ was estimated to be $43.7 \mathrm{~L} / \mathrm{h}$, and the intersubject variability on $\mathrm{CL} / \mathrm{F}$ was $60 \%$ with a $40 \%$ intrasubject variability on fraction absorbed. ${ }^{25,26}$ It is important to mention that patients in both DUET trials were also treated with darunavir $600 \mathrm{mg} /$ ritonavir $100 \mathrm{mg} /$ twice a day, drugs that interact with etravirine.

Etravirine is $99.6 \%$ protein bound, primarily to albumin. ${ }^{13}$ Maximal plasma concentration $\mathrm{T}_{\max }$ is reached in 2.5-4 hours, with an elimination half-life of 30-40 hours, which suggests that once-a-day administration is a feasible option. ${ }^{19,26}$ A multiple-dose pharmacokinetic study comparing etravirine monotherapy $200 \mathrm{mg}$ twice a day with $400 \mathrm{mg}$ once a day in healthy HIV-negative individuals was conducted. The systemic exposure was similar with a mean (SD) $\mathrm{AUC}_{12}$ of $8,195(2,428) \mathrm{ng} / \mathrm{h} / \mathrm{mL}$ and mean $(\mathrm{SD}) \mathrm{AUC}_{24}$ of 17,220 $(5,009) \mathrm{ng} / \mathrm{h} / \mathrm{mL}$ for the twice-a-day vs once-a-day dose, respectively. ${ }^{26} \mathrm{The}_{\mathrm{min}}$ of etravirine was approximately $27 \%$ 
lower for the once-a-day dose, and the $\mathrm{C}_{\text {max }}$ of etravirine was approximately $45 \%$ higher for the once-a-day dose. ${ }^{26}$

The pharmacokinetics of etravirine is unchanged in patients with mild to moderate hepatic impairment. Etravirine has reduced $\mathrm{CL} / \mathrm{F}$ in patients with hepatitis $\mathrm{B}$ or $\mathrm{C}$ coinfection; however, no dose adjustment is necessary. ${ }^{27}$ The pharmacokinetics of etravirine has not been studied in patients with renal impairment. ${ }^{13}$

\section{Pharmacodynamics}

The DUET-1 and DUET-2 multisite, double-blind, randomized, placebo-controlled phase III trials demonstrated superior virologic response when etravirine was compared with placebo, and when added to a combination regimen that included ritonavir-boosted darunavir. ${ }^{28-30}$ Factors predicting virologic response, defined as the proportion of patients with viral loads less than 50 copies $/ \mathrm{mL}$ at 48 weeks, included lower baseline viral load, higher baseline CD4 cell count, better adherence, number of active agents in the background regimen, and baseline fold change $(\mathrm{FC})$ in $\mathrm{EC}_{50}$ to etravirine. ${ }^{30}$ Pharmacokinetic parameters of $\mathrm{AUC}_{12}$ and $\mathrm{C}_{\text {min }}$ did not predict virologic suppression at week $48 .{ }^{30}$ Other factors, such as age, sex, race, and HIV clade, were not predictive of virologic response to etravirine at 48 weeks. ${ }^{30}$

\section{Metabolism}

Etravirine is a substrate of the hepatic cytochrome P450, and primarily metabolized by CYP3A4, CYP2C9, and CYP2C19, with its metabolites undergoing glucuronidation. Etravirine is an inducer of CYP3A4 and an inhibitor of CYP2C9, CYP2C19, and P-glycoprotein; therefore, coadministration of drugs that are substrates of CYP3A4, CYP2C9, and CYP2C19 or are transported by P-glycoprotein may alter the therapeutic effect or adverse reaction profile of the coadministered drug. ${ }^{13,26}$ Etravirine concentrations may also be affected by drugs that alter CYP3A4, CYP2C9, or CYP2C19 activity and are expected to be higher in patients with reduced CYP2C9 or CYP219 activity.

\section{Drug interactions}

Since etravirine has mixed effects on the isoenzymes of the cytochrome P450, the potential drug interactions with NNRTIs, PIs, azoles antifungals, clarithromycin, rifamycins and other drugs, are extensive (Table 1). Etravirine should not be coadministered with unboosted PIs or with ritonavirboosted tipranavir. Coadministration with ritonavir-boosted fosamprenavir results in high exposure to fosamprenavir with potential toxicity; therefore, coadministration is discouraged.
Coadministration with atazanavir $300 \mathrm{mg} /$ ritonavir $100 \mathrm{mg}$ results in a decrease in the atazanavir $\mathrm{C}_{\min }$ by $38 \%$; therefore, the authors suggest increasing the atazanavir dose to $400 \mathrm{mg}$ with $100 \mathrm{mg}$ of ritonavir. ${ }^{13,26}$ Coadministration of etravirine and the new integrase inhibitors (raltegravir and elvitegravir) has been evaluated in healthy volunteers. When raltegravir and etravirine were used at the recommended doses of 400 and $200 \mathrm{mg}$ twice a day, respectively, there was a slight increase in etravirine exposure and a small decrease in the raltegravir exposure that were not clinically significant. ${ }^{31}$ Similarly, no clinically relevant interaction was observed when elvitegravir and ritonavir at the dose of 150 and $100 \mathrm{mg}$ once a day, respectively, were coadministered with etravirine $200 \mathrm{mg}$ twice a day. ${ }^{32}$

Coadministration of etravirine with CYP450 inducers, such as the anticonvulsants phenobarbital, phenytoin, and carbamazepine, as well as coadministration with the rifamycins, rifampin or rifapentine, is contraindicated. However, rifabutin, a substrate and an inducer of CYP3A4, can be used in conjunction with etravirine without clinically significant interaction. $^{13}$

Fluconazole and voriconazole are inhibitors of CYP3A, CYP2C9, and CYP2C19, and coadministration with etravirine resulted in a slight increase in etravirine steady-state exposure. The voriconazole and fluconazole exposures were virtually unchanged; therefore, dose adjustment is not necessary. ${ }^{26,33}$ Itraconazole and ketoconazole are substrates and potent inhibitors of CYP3A4 and could increase the etravirine exposure. In addition, etravirine could decrease the exposure of ketoconazole and itraconazole; therefore, caution should be exercised when etravirine is coadministered with these antifungals. ${ }^{34}$ Clarithromycin is an inhibitor of CYP3A4 and when coadministered with etravirine, caused a $40 \%$ increase in etravirine exposure. The overall exposure of clarithromycin was reduced by $59 \%$, while the 14-hydroxy-clarithromycin exposure was increased. Since the 14-hydroxy-clarithromycin has decreased activity against Mycobacterium avium complex, it is recommended to consider azithromycin as an alternative treatment for $M$. avium complex infection. ${ }^{26}$ For a comprehensive review of the etravirine interactions with different medications, the reader is referred to the etravirine prescribing information. ${ }^{13}$

\section{Efficacy studies}

A double-blind, phase IIa clinical trial among HIV-infected, treatment-naive subjects randomized 2:1 to receive either etravirine $900 \mathrm{mg}$ twice a day (PEG 4000 formulation) or 
Table I Significant etravirine drug interactions ${ }^{13,26,34,47}$

\begin{tabular}{|c|c|c|c|}
\hline Drug & Effect on ETR & Effect on drug & Comment \\
\hline \multicolumn{4}{|l|}{ Protease inhibitors ${ }^{\mathrm{a}}$} \\
\hline $\begin{array}{l}\text { Saquinavir/ritonavir } \\
1000 / 100 \mathrm{mg} \text { twice a day }\end{array}$ & $33 \% \downarrow$ AUC, $29 \% \downarrow C_{\text {min }}$ & $20 \% \downarrow C_{\min }$ & No dose adjustment \\
\hline $\begin{array}{l}\text { Atazanavir/ritonavir } \\
300 / 100 \mathrm{mg} \text { every day }\end{array}$ & $\begin{array}{l}30 \% \uparrow \text { in } C_{\max } \\
A \cup C \text { and } C_{\min }\end{array}$ & $\begin{array}{l}38 \% \downarrow \text { in } C_{\text {min, }} \\
14 \% \downarrow \text { in } A U C\end{array}$ & $\uparrow$ ATV dose ${ }^{b}$ \\
\hline $\begin{array}{l}\text { Fosamprenavir/ritonavir } \\
700 / 100 \mathrm{mg} \text { twice a day }\end{array}$ & No effect & $\begin{array}{l}\uparrow 62 \%-77 \% \mathrm{C}_{\max } \\
\text { AUC and } C_{\min }\end{array}$ & Avoid use \\
\hline $\begin{array}{l}\text { Lopinavir/ritonavirc } \\
400 / 100 \mathrm{mg} \text { twice a day }\end{array}$ & \multicolumn{2}{|c|}{$400 / 100 \mathrm{mg}$ twice a day } & No dose adjustment \\
\hline $\begin{array}{l}\text { Tipranavir/ritonavir } \\
500 / 200 \mathrm{mg} \text { twice a day }\end{array}$ & $76 \% \downarrow A \cup C, 82 \% \downarrow C_{\min }$ & $24 \% \uparrow C_{\min }$ & Avoid use \\
\hline $\begin{array}{l}\text { Darunavir/ritonavir } \\
600 / 100 \mathrm{mg} \text { twice a day }\end{array}$ & $37 \% \downarrow \mathrm{AUC}, 49 \% \downarrow \mathrm{C}_{\text {min }}$ & I5\% $\uparrow A U C$ & No dose adjustment \\
\hline \multicolumn{4}{|l|}{ Reverse transcriptase inhibitors } \\
\hline Didanosine 400 mg every day & No effect & No effect & No dose adjustment \\
\hline $\begin{array}{l}\text { Tenofovir DF } 300 \text { mg every day } \\
\text { Integrase inhibitor }\end{array}$ & $19 \% \downarrow A \cup C, 18 \% \downarrow C_{\text {min }}$ & $19 \% \uparrow C_{\min }$ & No dose adjustment \\
\hline Raltegravir 400 mg twice a day & $17 \% \uparrow C_{\min }$ & $34 \% \downarrow C_{\min }$ & No dose adjustment \\
\hline \multicolumn{4}{|l|}{$150 / 100 \mathrm{mg}$ every day } \\
\hline \multicolumn{4}{|l|}{ CCR5 antagonists } \\
\hline Maraviroc $300 \mathrm{mg}$ twice a day & No effect & $53 \% \downarrow A \cup C, 39 \% \downarrow C_{\min }$ & $\uparrow$ Maraviroc to $600 \mathrm{mg}$ twice a day \\
\hline \multicolumn{4}{|l|}{ Other drugs } \\
\hline Rifabutin 300 mg every day & $35 \% \downarrow C_{\min }, 37 \% \downarrow$ AUC & $24 \% \downarrow C_{\min }$ & No dose adjustment \\
\hline Clarithromycin $500 \mathrm{mg}$ twice a day & $42 \% \uparrow A U C, 46 \% \uparrow C_{\min }$ & $39 \% \downarrow A U C, 53 \% \downarrow C_{\min }$ & Avoid use ${ }^{e}$ \\
\hline Omeprazole 40 mg every day & $41 \% \uparrow A U C$ & Not available & No dose adjustment \\
\hline Ranitidine $150 \mathrm{mg}$ twice a day & $14 \% \downarrow$ AUC & Not available & No dose adjustment \\
\hline Atorvastin $40 \mathrm{mg}$ every day & No effect & $37 \% \downarrow$ AUC & No dose adjustment \\
\hline Paroxetine $20 \mathrm{mg}$ every day & No effect & No effect & No dose adjustment \\
\hline Methadone $60-130 \mathrm{mg} /$ day & No effect & No effect & Monitor for withdrawal \\
\hline Sildenafil $50 \mathrm{mg}$ single dose & No effect & $57 \% \downarrow A \cup C$ & Sildenafil dose needs to be $\uparrow$ \\
\hline
\end{tabular}

a Unboosted protease inhibitors should not be used with etravirine; ' ${ }^{\mathrm{T}} \mathrm{To} 400 \mathrm{mg}$ with $100 \mathrm{mg}$ of ritonavir every day; ${ }^{\mathrm{C}}$ Tablet; ${ }^{\mathrm{d}} \mathrm{n}$ the absence of boosted protease inhibitor. If ritonavir-boosted darunavir is combined with etravirine and maraviroc, the maraviroc dose should be $150 \mathrm{mg}$ twice a day; ${ }^{\circ} \mathrm{Consider}$ using azithromycin; $\mathrm{f}$ Methadone maintenance dose may need to be adjusted.

Abbreviations: AUC, area under the plasma concentration-time curve; $C_{\min }$ and $C_{\max }$, minimum and maximum plasma concentrations; $A T V$, atazanavir; ETR, etravirine; DF, disoproxil fumarate.

matched placebo as monotherapy was conducted as a proof of concept. ${ }^{19}$ After 7 days, patients treated with etravirine $(\mathrm{n}=12)$ had a mean decrease in plasma HIV RNA of $1.99 \log 10$ copies $/ \mathrm{mL}$ compared with $0.06 \log 10$ copies $/ \mathrm{mL}$ in the placebo arm $(\mathrm{n}=7 ; P<0.001){ }^{19}$

In an open-label, phase IIa trial, 16 individuals receiving either efavirenz or nevirapine on virologic failure, defined as having HIV RNA viral load $>2000$ copies $/ \mathrm{mL}$ and documented high-level phenotypic NNRTI resistance, substituted their failing NNRTI for etravirine $900 \mathrm{mg}$ twice a day for 7 days. After 7 days of treatment, a median $0.89 \log _{10}$ copies/ $\mathrm{mL}$ decline in HIV RNA load was observed and 7 individuals (44\%) had greater than $1 \log _{10}$ decline in HIV RNA load. ${ }^{20}$

TMC125-C223 was an open-label, partially blinded, phase II randomized clinical trial, which evaluated the efficacy of 2 doses of the TF035 (granular layered) formulation of etravirine at 400 or $800 \mathrm{mg}$ twice a day in addition to 2 or more approved antiretroviral agents, such as nucleoside reverse transcriptase inhibitors (NRTIs) and lopinavir/ ritonavir and/or enfuvirtide. The comparator arm was an optimized regimen consisting of 3 or more FDA-approved drugs from 2 or more classes. ${ }^{21}$ The 199 patients studied were randomized 2:2:1 to etravirine $400 \mathrm{mg}, 800 \mathrm{mg}$, and control, and had evidence of genotypic resistance to firstgeneration NNRTIs and at least 3 primary PI mutations. The mean reduction in HIV RNA from baseline at week 24 was $1.04,1.18$, and $0.19 \log _{10}$ copies $/ \mathrm{mL}$ for etravirine $400 \mathrm{mg}$ twice a day, $800 \mathrm{mg}$ twice a day, and the control group, respectively $(P<0.05$ for both etravirine groups compared with control). ${ }^{21}$ There was no significant difference in efficacy between the 2 etravirine doses; however, in patients not treated with enfuvirtide, or in patients treated 
with only 1 active agent (other than etravirine), the 800-mg dosage had greater virologic success. ${ }^{21}$ TMC125-C227 was a phase II, randomized, controlled, open-label 48-week trial comparing the efficacy of etravirine with an investigatorselected PI in NNTRI-resistant, PI-naive HIV-infected patients. Patients were randomized to etravirine $800 \mathrm{mg}$ twice a day $(n=59)$ or the control PI $(n=57)$, plus 2 NRTIs. ${ }^{35}$ This trial was prematurely stopped when an unplanned interim analysis revealed suboptimal virologic response in individuals receiving etravirine in comparison with the control PI arm. The suboptimal virologic response in the etravirine arm was attributed to the high level of baseline NRTI and NNRTI resistance that made this arm virologicaly inferior to the PI-based control regimen. Therefore, the use of etravirine plus NRTIs alone will be suboptimal in PI-naive patients with first-line virologic failure on an NNRTI-based regimen. ${ }^{35}$

The DUET-1 and DUET-2 are multinational, randomized, double-blind, placebo-controlled phase III trials with identical design and conducted in different areas of the world. Treatment-experienced adults with virologic failure on stable antiretroviral therapy, documented NNRTI genotypic resistance, viral load over 5000 copies $/ \mathrm{mL}$, and 3 or more primary PI mutations were randomly assigned to receive $200 \mathrm{mg}$ of etravirine or placebo twice a day. All patients also received $600 \mathrm{mg}$ of darunavir with $100 \mathrm{mg}$ of ritonavir twice a day and investigator-selected NRTI. Enfuvirtide was optional. The primary intent-to-treat end point was a confirmed HIV RNA viral load of less than 50 copies/mL at week 24 using the US FDA time-toloss of virologic response algorithm. ${ }^{28,29}$ At week 24, in DUET-1, 170 (56\%) patients in the etravirine group and $119(39 \%)$ patients in the placebo group achieved a HIV RNA load of $<50$ copies/mL $(P=0.005)$. HIV RNA viral load $<400$ copies/mL was observed in 224 (74\%) patients in the etravirine group and in $158(51 \%)$ patients in the placebo group at week $24(P=0.0001)$. The mean decline in viral load from baseline in the etravirine group was $2.41 \log _{10}$ copies/mL compared with $1.70 \log _{10}$ copies $/ \mathrm{mL}$ in the placebo group $(P<0.0001)$. In addition, a greater increase in mean CD4 cell count was observed in the etravirine group compared with the placebo group at 89 vs 64 cells $/ \mu \mathrm{L}$, respectively $(P=0.0002) .{ }^{28}$ In the DUET2 , by week $24,183(62 \%)$ patients in the etravirine group and $129(44 \%)$ patients in the placebo group achieved a HIV RNA load of $<50$ copies $/ \mathrm{mL}(P=0.0003)$. HIV RNA viral load $<400$ copies/mL was observed in 221 (75\%) patients in the etravirine group and in $159(54 \%)$ patients in the placebo group at week $24(P=0.0001)$. The mean decline in viral load from baseline in the etravirine group was $2.34 \log _{10}$ copies/mL compared with $1.68 \log _{10}$ copies $/ \mathrm{mL}$ in the placebo group $(P<0.0001)$. The mean change in CD4 cell count from baseline was 78 vs 66 cells/ $\mu \mathrm{L}$ for the etravirine and placebo groups, respectively $(P=0.36) .{ }^{29}$

Pooled 48-week analysis of the DUET studies showed durable virologic efficacy, with significantly more patients in the etravirine arm than in the placebo arm achieving viral load $<50$ copies/mL (61\% vs $40 \%$, respectively; $P<0.0001) .{ }^{30}$ Patients taking etravirine achieved virologic response significantly more quickly than patients taking placebo (median 15.7 and 32.7 weeks for etravirine and placebo, respectively; $P<0.0001)$. The mean 48 -week decline in viral load from baseline in the etravirine group was $2.25 \log _{10}$ copies/mL compared with $1.49 \log _{10}$ copies/mL in the placebo group $(P<0.0001) .{ }^{30}$ The mean increase in CD4 cell count was significantly higher in the etravirine group compared with the placebo group (98.2 vs 72.9 cells $/ \mu \mathrm{L}$, respectively; $P=0.0006)$. In addition, there were fewer AIDS-defining events or death in the etravirine group compared with the placebo group, with $35(6 \%)$ vs $59(10 \%)$ events, respectively $(P=0.04) .{ }^{30}$ Factors found to predict virologic response at 48 weeks were lower baseline viral load, higher CD4 cell count, greater adherence, number of active agents in the background regimen, and less than 3 baseline $\mathrm{FC}$ in $\mathrm{EC}_{50}$ to etravirine.

Recently, a phase II, multicenter ANRS 139 TRIO trial evaluated the virologic response to a combination of 3 novel agents among patients on virologic failure with NRTI-, NNRTI-, and PI-resistant HIV. A total of 103 patients were enrolled and treated with raltegravir, darunavir, ritonavir, and etravirine at FDA-approved doses. ${ }^{36}$ The novel combination was well tolerated, with only 1 patient discontinuing treatment due to adverse events. At week $48,86 \%$ of patients had a HIV RNA viral load of $<50$ copies/mL and a median CD4 cell count increase of 108 cells $/ \mu \mathrm{L} .^{36}$

\section{Safety and tolerability}

The 48-week pooled analysis on all 1,203 patients enrolled in DUET-1 and DUET-2 revealed no safety concerns, with the majority of adverse events being grade 1 or 2 in severity. The incidence of grade 3 or 4 adverse events was comparable between the etravirine and the placebo groups, and the mortality in the etravirine group was considered not related to study drug (Table 2). ${ }^{30}$ Rash was the only adverse event to occur significantly more frequently in the etravirine group compared 
Table 2 Adverse events reported in the DUET-I and DUET-2 studies at week $48^{30}$

\begin{tabular}{|c|c|c|}
\hline Adverse event & $\begin{array}{l}\text { ETV + OBT } \\
(N=599)\end{array}$ & $\begin{array}{l}\text { Placebo + OBT } \\
(\mathrm{N}=604)\end{array}$ \\
\hline Any adverse event, n (\%) & $575(96)$ & $580(96)$ \\
\hline Grade 3 or 4 adverse event & $199(33)$ & $211(35)$ \\
\hline Serious adverse events & $118(20)$ & $|4|(23)$ \\
\hline Rash (any type) & 115 (19) & $66(11)$ \\
\hline Diarrhea & $118(18)$ & $142(24)$ \\
\hline Nervous system & $103(17)$ & $119(20)$ \\
\hline Psychiatric & $100(17)$ & II 8 (20) \\
\hline Nausea & $89(15)$ & $77(13)$ \\
\hline Headache & $65(\mathrm{II})$ & $77(13)$ \\
\hline Hepatic & $39(7)$ & $37(6)$ \\
\hline \multicolumn{3}{|l|}{ Adverse events leading to } \\
\hline Discontinuation & $43(7)$ & $34(6)$ \\
\hline Deaths & $12(2)$ & $20(3)$ \\
\hline \multicolumn{3}{|c|}{ Selected grade 2-4 laboratory abnormalities } \\
\hline \multicolumn{3}{|c|}{ Triglycerides } \\
\hline Grade 2 (500-700 mg/dL) & $54(9)$ & $43(7)$ \\
\hline Grade $3(75 \mathrm{I}-1200 \mathrm{mg} / \mathrm{dL})$ & $34(6)$ & $24(4)$ \\
\hline Grade $4(>1200 \mathrm{mg} / \mathrm{dL})$ & $21(4)$ & II (2) \\
\hline \multicolumn{3}{|l|}{ Pancreatic amylase } \\
\hline Grade $2(>I .5-2 \times$ ULN) & $40(7)$ & $46(8)$ \\
\hline Grade $3(>2-5 \times$ ULN $)$ & $44(7)$ & $5 \mathrm{I}(8)$ \\
\hline Grade $4(>5 \times$ ULN $)$ & $9(2)$ & $6(1)$ \\
\hline \multicolumn{3}{|l|}{ Total cholesterol } \\
\hline Grade $2(240-300 \mathrm{mg} / \mathrm{dL})$ & $117(20)$ & $101(17)$ \\
\hline Grade $3(>300 \mathrm{mg} / \mathrm{dL})$ & $48(8)$ & $32(5)$ \\
\hline \multicolumn{3}{|l|}{ LDL cholesterol } \\
\hline Grade $2(160-190 \mathrm{mg} / \mathrm{dL})$ & $76(13)$ & $69(12)$ \\
\hline Grade 3 (>190 mg/dL) & $42(7)$ & $39(7)$ \\
\hline \multicolumn{3}{|l|}{ Alanine aminotransferase } \\
\hline Grade $2(2.6-5 \times$ ULN $)$ & $37(6)$ & $33(6)$ \\
\hline Grade $3(5.1-10 \times$ ULN) & $16(3)$ & $10(2)$ \\
\hline Grade $4(>10 \times$ ULN $)$ & $6(1)$ & $2(<1)$ \\
\hline \multicolumn{3}{|l|}{ Aspartate aminotransferase } \\
\hline Grade $2(2.6-5 \times$ ULN $)$ & $37(6)$ & $49(8)$ \\
\hline Grade $3(5.1-10 \times$ ULN $)$ & $16(3)$ & $10(2)$ \\
\hline Grade $4(>10 \times$ ULN $)$ & $3(<1)$ & $2(<1)$ \\
\hline
\end{tabular}

Abbreviations: ETV, etravirine; OBT, optimized background therapy.

with the placebo recipients $(19.2 \%$ vs $10.9 \% ; P=0.0001)$. Within the etravirine group, grade 1 or 2 rash occurred in $17.9 \%$ and grade 3 in $1.3 \%$, with no grade 4 reported among patients exposed to etravirine. Rash occurred mainly during the second week of therapy with a median time to onset of 14 days (range: 1-472 days). It generally resolved within 2 weeks on continued therapy with a median duration of 15 days (range: 1-402 days). Treatment discontinuation due to etravirine-associated rash occurred in $2.2 \%$ of patients. ${ }^{30}$ The incidence of etravirine-associated rash was higher in women than in men $(30 \%$ vs $18 \% ; P=0.03)$. Patients with a history of NNRTI-related rash did not appear to have a higher risk for developing etravirine-related rash compared with patients with no history of NNRTI-related rash ( $22 \%$ vs $19 \%$, respectively). There was no association between baseline CD4 cell count and etravirine-associated rash regardless of sex. The overall incidence of neuropsychiatric disorders was low, and disorders were mostly grade 1 or 2 events and comparable between the etravirine and placebo groups. The incidence of hepatic adverse events and laboratory abnormalities, including hepatic and lipid parameters, were mostly grade 1 or 2 in severity and comparable between the etravirine and the placebo groups (Table 2). ${ }^{30}$

\section{Etravirine resistance}

Etravirine-resistance-associated mutations (RAM) have been characterized both in vitro and in vivo. ${ }^{14,37}$ Unlike the first-generation NNRTIs, etravirine requires multiple mutations for the development of resistance (Table 3). ${ }^{37}$ The impact of baseline genotype on virologic response to etravirine among subjects failing first-generation NNRTI was investigated in the DUET- 1 and DUET- 2 trials. ${ }^{28,29}$ Of the 44 NNRTI RAM, 13 mutations were initially identified by their association, with at least a $25 \%$ decline in response to etravirine compared with a subgroup of patients with no detectable NNRTI RAM at baseline. ${ }^{38}$ Recently, further analysis of the pooled DUET- 1 and DUET-2 data has expanded the number of etravirine RAM to 17, with Y181C and G190A being the most prevalent at baseline and present in $32 \%$ and $23.3 \%$ of patients, respectively, enrolled in the DUET studies (Table 3). ${ }^{39}$ The genotypic and phenotypic correlates of virologic response to etravirine defined as a HIV RNA load $<50$ copies $/ \mathrm{mL}$ at 24 weeks were examined by the pooled analysis of the DUET- 1 and DUET- 2 trials. A weighted genotypic score was developed by assigning a relative weight factor to each etravirine RAM according to its impact on virologic response and $\mathrm{FC}$ in the $\mathrm{EC}_{50}$. The relative weight factors were determined with random forest and linear modeling techniques, using matching genotypic and phenotypic data with virologic outcomes from the DUET trials and from a panel of NNRTI-resistant, recombinant HIV-1 clinical isolates. ${ }^{37}$ Among the 17 etravirine RAMs, the highest weight factor was assigned to Y181I and Y181V, with a weight factor of 3, followed by K101P, L100I, Y181C, and M230L, with a weight factor of 2.5 (Table 3). Etravirine-weighted genotypic score was graded as highest virologic response associated with the lowest score of $0-2$, intermediate virologic response of 2.5-3.5, and reduced virologic response of $\geq 4$, and correlated with virologic suppression at 24 weeks in $74.4 \%, 52 \%$ and $37.7 \%$ of patients, respectively (Table 4) ${ }^{37}$ The effect of baseline etravirine FC 
Table 3 Genotype weight factor and FC in $\mathrm{EC}_{50}$ of etravirine-resistance-associated mutations ${ }^{37}$

\begin{tabular}{|c|c|c|c|c|}
\hline \multirow[t]{2}{*}{ Etravirine RAM } & \multirow[t]{2}{*}{ Genotype weight factor } & \multicolumn{2}{|c|}{$\begin{array}{l}\text { Etravirine FC in } \mathrm{EC}_{50} \\
\text { in HIV-I clinical isolates }\end{array}$} & \multirow[t]{2}{*}{$\begin{array}{l}\text { Etravirine } F C \text { in } \mathrm{EC}_{50} \\
\text { in a single } \mathrm{SDM}\end{array}$} \\
\hline & & Median & $n$ & \\
\hline YI8II & 3.0 & 42.0 & 34 & 12.5 \\
\hline YI8IV & 3.0 & 10.4 & 28 & 17.4 \\
\hline KIOIP & 2.5 & 22.3 & 65 & 6.2 \\
\hline LIOOI & 2.5 & 6.7 & 264 & 1.8 \\
\hline YI8IC & 2.5 & 4.4 & 552 & 3.9 \\
\hline M230L & 2.5 & 4.3 & 20 & 3.4 \\
\hline EI38A & 1.5 & 2.9 & 44 & 2.0 \\
\hline VI06I & 1.5 & 2.6 & 63 & NA \\
\hline GI90S & 1.5 & 0.8 & 32 & 0.2 \\
\hline VI79F & 1.5 & NA & 0 & 0.1 \\
\hline V90I & 1.0 & 2.0 & 97 & 1.5 \\
\hline VI79D & 1.0 & 1.7 & 33 & 2.6 \\
\hline KIOIE & 1.0 & 1.5 & 24 & 1.7 \\
\hline $\mathrm{KIOIH}$ & 1.0 & I.I & 8 & 1.3 \\
\hline A98G & 1.0 & 1.0 & 127 & 2.5 \\
\hline VI79T & 1.0 & 0.9 & 2 & 0.8 \\
\hline G190A & 1.0 & 0.8 & 226 & 0.8 \\
\hline
\end{tabular}

${ }^{2} \mathrm{VI79F}$ when present was always associated with YI8IC.

Abbreviations: $\mathrm{EC}_{50}, 50 \%$ effective concentration; RAM, resistance-associated mutations; FC, fold change; SDM, site directed mutant.

in $\mathrm{EC}_{50}$ on virologic suppression at week 24 was evaluated by analysis of covariance to determine the clinical cut-off values. The $\mathrm{EC}_{50}$ was derived from the Virco phenotype assay (Antivirogram ${ }^{\circledR}$; Virco BVBA, Mechelen, Belgium). Patients with a baseline etravirine $\mathrm{FC}$ in $\mathrm{EC}_{50}$ of 3 or less had the highest virologic response (70.6\%) (Table 4). ${ }^{37}$ Patients with intermediate response ( $50 \%$ virologic suppression) had an etravirine $\mathrm{EC}_{50} \mathrm{FC}$ of $>3$ to $\leq 13$, and patients with an etravirine $\mathrm{EC}_{50} \mathrm{FC}$ of $>13$ had reduced response, with virologic suppression in only $36.7 \%$ of patients (Table 4 ). ${ }^{37}$

An alternate analysis of biological and clinical cut-off values was performed by Coakley et al on 199 baseline samples using the PhenoSense ${ }^{\text {TM }}$ HIV (Monogram Biosciences, San Francisco, California, USA). ${ }^{40}$ The lower clinical cut-off value for etravirine was defined as the $\mathrm{FC}$ above which HIV RNA response was first observed to decline relative to the reference population. Virologic outcomes were evaluated on the DUET studies at weeks 2, 4, 8, and 24 in relation to baseline etravirine FC. The biological cut-off was defined as the ninety-ninth percentile of etravirine $\mathrm{FC}$ values from 1,693 viral isolates without mutations conferring resistance to NRTIs, NNRTIS, or PIs. ${ }^{40}$ In a model adjusted for the activity of the background therapy, the activity of etravirine was observed to be reduced at a FC $>2.9$. Further studies from the same group, using the lower clinical cut-off value of $2.9 \mathrm{FC}$ to define reduced susceptibility, correlated a novel etravirine RAM weighting score with the relative impact on etravirine susceptibility in which a score of 4 or more defined reduced susceptibility. ${ }^{41}$ Mutations with a score of 4 were L100I, K101P, and Y181C/I/V. A score of 3 was assigned to E138A/G, V179E, G190Q, M230L, and K238N. A score of 2 was assigned to K101E, V106A/I, E138K, V179L, Y188L, and G190S. A score of 1 was assigned to V90I, K101H, V106M, E138Q, V179D/F/M, Y181F, V189I, G190E/T, $\mathrm{H} 221 \mathrm{Y}, \mathrm{P} 225 \mathrm{H}$, and K238T. ${ }^{41,42}$ Contrary to the first-generation NNRTIs, the etravirine resistance patterns are more complex and continue to evolve. Recently, the combination of Y181C with N348I and 399D mutations, not included among

Table 4 Relationship between genotypic and phenotypic susceptibility categories using the etravirine-weighted genotypic score ${ }^{37}$

\begin{tabular}{|c|c|c|c|c|}
\hline & \multirow[t]{2}{*}{ Patients, n (\%) } & \multicolumn{3}{|c|}{ Baseline etravirine fold change in $\mathrm{EC}_{50}, \mathrm{n}(\%)$} \\
\hline & & $\leq 3(S)$ & $>3$ to $\leq 13(1)$ & $>13(R)$ \\
\hline \multicolumn{5}{|c|}{ Etravirine-weighted genotypic score } \\
\hline $0-2(S)$ & $225(55.8)$ & $208(92.4)$ & $16(7.1)$ & I $(0.4)$ \\
\hline $2.5-3.5(\mathrm{I})$ & $101(25.1)$ & $42(4 \mid .6)$ & $31(30.7)$ & $28(27.7)$ \\
\hline$>4(\mathrm{R})$ & $77(19.1)$ & $19(24.7)$ & $27(35.1)$ & $31(40.3)$ \\
\hline
\end{tabular}

Abbreviations: $\mathrm{EC}_{50}, 50 \%$ effective concentration; S, susceptible; I, intermediate; $\mathrm{R}$, resistant. 
the etravirine RAM, caused a 6.4- to 12.6-fold reduction in etravirine susceptibility. ${ }^{43,44}$

\section{Patient perspective and conclusion}

Etravirine, a second-generation NNRTI, received FDA approval in January 2008 for the management of treatment-experienced, HIV-infected adults with NNRTIresistant viruses. It has a high genetic barrier to resistance and is active against nevirapine- and efavirenz-resistant viruses. Etravirine is safe and well tolerated, it does not have the neuropsychiatric or hepatic side effects of efavirenz or nevirapine, and its safety profile is comparable to placebo with the exception of rash. Rash was grade 1 or 2 in the great majority of patients and was self-limited. History of NNRTI-related rash was not a predisposing factor. Etravirine is a pregnancy category $\mathrm{B}$ drug; its safety, pharmacokinetic profile, and efficacy have not been studied in pregnant women. Pediatric phase I/II studies are being conducted, and preliminary data suggest that it is safe and well tolerated. Pharmacokinetic studies in children between 6 and 17 years have shown that a dose of $5.2 \mathrm{mg} / \mathrm{kg}$ twice a day leads to exposure comparable to exposure by the adult dose of 200 mg twice a day. ${ }^{45}$ In the DUET- 1 and DUET- 2 phase III efficacy trials, etravirine was always used in combination with ritonavir-boosted darunavir, a PI with antiviral activity in PI treatment-experienced patients. With the recent FDA approval of darunavir, raltegravir, and etravirine (and maraviroc for CCR5 tropic viruses), all with antiviral activity against multiple-drug-resistant HIV isolates, it is now possible for treatment-experienced patients to aim for virologic suppression comparable to treatment-naive patients as has been shown in the TRIO trial. ${ }^{36}$ In this trial, $86 \%$ of patients with multiple-drug-resistant HIV treated with raltegravir-, etravirine-, and ritonavir-boosted darunavir had a HIV RNA load of $<50$ copies $/ \mathrm{mL}$ at 48 weeks. ${ }^{36}$

In addition to the virologic efficacy, analysis from the DUET trials has shown a significant reduction in the hospitalization rate and in the number of hospitalization days among patients enrolled in the etravirine arm compared with the placebo arm. ${ }^{46}$ Ongoing studies on the pharmacokinetic interaction with newer agents; the safety, tolerability, and pharmacokinetic studies in children; and the prospect of once-a-day regimen due to the long half-life are subject to investigation.

\section{Acknowledgments}

The author thanks Maria Rosario Araneta, PhD, and Edmund Capparelli, Pharm D, for their critical review of the manuscript.

\section{Disclosures}

The author reports no conflicts of interest in this work.

\section{References}

1. Palella FJ Jr, Delaney KM, Moorman AC, et al. Declining morbidity and mortality among patients with advanced human immunodeficiency virus infection. HIV Outpatient Study Investigators. $N$ Engl $J$ Med. 1998;338:853-860.

2. Mocroft A, Ledergerber B, Katlama C, et al. Decline in the AIDS and death rates in the EuroSIDA study: an observational study. Lancet. 2003;362:22-29.

3. Severe P, Leger P, Charles M, et al. Antiretroviral therapy in a thousand patients with AIDS in Haiti. N Engl J Med. 2005;353:2325-2334.

4. Nash D, Katyal M, Brinkhof MW, et al. Long-term immunologic response to antiretroviral therapy in low-income countries: a collaborative analysis of prospective studies. AIDS. 2008;22: 2291-2302.

5. Brinkhof MW, Boulle A, Weigel R, et al. Mortality of HIV-infected patients starting antiretroviral therapy in sub-Saharan Africa: comparison with HIV-unrelated mortality. PLoS Med. 2009;6:e1000066.

6. Hammer SM, Eron JJ Jr, Reiss P, et al. Antiretroviral treatment of adult HIV infection: 2008 recommendations of the International AIDS Society-USA panel. JAMA. 2008;300:555-570.

7. Wainberg MA. HIV resistance to nevirapine and other non-nucleoside reverse transcriptase inhibitors. J Acquir Immune Defic Syndr. 2003;34 Suppl 1:S2-S7.

8. Little SJ, Holte S, Routy JP, et al. Antiretroviral-drug resistance among patients recently infected with HIV. $N$ Engl J Med. 2002;347: 385-394.

9. Viani RM, Peralta L, Aldrovandi G, et al. Prevalence of primary HIV-1 drug resistance among recently infected adolescents: a multicenter adolescent medicine trials network for HIV/AIDS interventions study. J Infect Dis. 2006;194:1505-1509.

10. Descamps D, Chaix ML, Andre P, et al. French national sentinel survey of antiretroviral drug resistance in patients with HIV-1 primary infection and in antiretroviral-naive chronically infected patients in 2001-2002. J Acquir Immune Defic Syndr. 2005;38:545-552.

11. Little SJ, Frost SD, Wong JK, et al. Persistence of transmitted drug resistance among subjects with primary human immunodeficiency virus infection. J Virol. 2008;82:5510-5518.

12. Arrive E, Newell ML, Ekouevi DK, et al. Prevalence of resistance to nevirapine in mothers and children after single-dose exposure to prevent vertical transmission of HIV-1: a meta-analysis. Int J Epidemiol. 2007;36:1009-1021.

13. Intelence ${ }^{\circledR}$. (etravirine) [Package Insert]. Tibotec Therapeutics. Raritan, New Jersey, 2008. Available at: http://www.intelence-info.com/. Accessed Mar 6, 2010.

14. Andries K, Azijn H, Thielemans T, et al. TMC125, a novel nextgeneration nonnucleoside reverse transcriptase inhibitor active against nonnucleoside reverse transcriptase inhibitor-resistant human immunodeficiency virus type 1. Antimicrob Agents Chemother. 2004; $48: 4680-4686$.

15. De Corte BL. From 4,5,6,7-tetrahydro-5-methylimidazo[4,5,1-jk](1,4) benzodiazepin-2(1H)-one (TIBO) to etravirine (TMC125): fifteen years of research on non-nucleoside inhibitors of HIV-1 reverse transcriptase. J Med Chem. 2005;48:1689-1696.

16. Udier-Blagovic M, Tirado-Rives J, Jorgensen WL. Validation of a model for the complex of HIV-1 reverse transcriptase with nonnucleoside inhibitor TMC125. J Am Chem Soc. 2003;125:6016-6017.

17. Deeks S. Nonnucleoside reverse transcriptase inhibitor rsesistance. J Acquir Immune Defic Syndr. 2001;26:S25-S33.

18. Das K, Clark AD Jr, Lewi PJ, et al. Roles of conformational and positional adaptability in structure-based design of TMC125-R165335 (etravirine) and related non-nucleoside reverse transcriptase inhibitors that are highly potent and effective against wild-type and drug-resistant HIV-1 variants. $J$ Med Chem. 2004;47:2550-2560. 
19. Gruzdev B, Rakhmanova A, Doubovskaya E, et al. A randomized, double-blind, placebo-controlled trial of TMC125 as 7-day monotherapy in antiretroviral naive, HIV-1 infected subjects. AIDS. 2003;17:2487-2494.

20. Gazzard BG, Pozniak AL, Rosenbaum W, et al. An open-label assessment of TMC 125 - a new, next-generation NNRTI, for 7 days in HIV-1 infected individuals with NNRTI resistance. AIDS 2003;17:F49-F54

21. Nadler JP, Berger DS, Blick G, et al. Efficacy and safety of etravirine (TMC125) in patients with highly resistant HIV-1: primary 24-week analysis. AIDS. 2007;21:F1-F10.

22. Kakuda TN, Scholler-Gyure M, Workman C, et al. Single- and multipledose pharmacokinetics of etravirine administered as two different formulations in HIV-1-infected patients. Antivir Ther. 2008;13:655-661.

23. Scholler-Gyure M, Boffito M, Pozniak AL, et al. Effects of different meal compositions and fasted state on the oral bioavailability of etravirine. Pharmacotherapy. 2008;28:1215-1222.

24. Scholler-Gyure M, Kakuda TN, Van Solingen-Ristea R, Berckmans C, De Smedt G. Bioavailability of the $100 \mathrm{mg}$ etravirine tablet dispersed in water and of the $25 \mathrm{mg}$ pediatric tablet formulation. In: XVII International AIDS Conference; 2008 Aug 3-8, Mexico City, Mexico. Abstract MOPE 0184

25. Kakuda TN, Wade J, Snoeck E. Pharmacokinetics and pharmacodynamics of the NNRTI TMC125 in treatment experienced HIV-1 infected Patients: pooled 24-week results of DUET-1 and DUET-2. In: 15th Conference on Retroviruses and Opportunistic Infections; 2008 Feb 3-6, Boston, MA. Abstract 762.

26. Scholler-Gyure M, Kakuda TN, RaoofA, De Smedt G, Hoetelmans RM. Clinical pharmacokinetics and pharmacodynamics of etravirine. Clin Pharmacokinet. 2009;48:561-574.

27. Scholler-Gyure M, Kakuda TN, De Smedt G, et al. Effects of hepatic impairment on the steady-state pharmacokinetics of etravirine $200 \mathrm{mg}$ BID: an open-label, multiple-dose, controlled Phase I study in adults. Clin Ther. 2010;32:328-337.

28. Madruga JV, Cahn P, Grinsztejn B, et al. Efficacy and safety of TMC125 (etravirine) in treatment-experienced HIV-1-infected patients in DUET-1: 24-week results from a randomised, double-blind, placebocontrolled trial. Lancet. 2007;370:29-38.

29. Lazzarin A, Campbell T, Clotet B, et al. Efficacy and safety of TMC125 (etravirine) in treatment-experienced HIV-1-infected patients in DUET-2: 24-week results from a randomised, double-blind, placebocontrolled trial. Lancet. 2007;370:39-48.

30. Katlama C, Haubrich R, Lalezari J, et al. Efficacy and safety of etravirine in treatment-experienced, HIV-1 patients: pooled 48 week analysis of two randomized, controlled trials. AIDS. 2009;23:2289-2300.

31. Anderson MS, Kakuda TN, Hanley W, et al. Minimal pharmacokinetic interaction between the human immunodeficiency virus nonnucleoside reverse transcriptase inhibitor etravirine and the integrase inhibitor raltegravir in healthy subjects. Antimicrob Agents Chemother. 2008;52:4228-4232.

32. Ramanathan S, Kakuda TN, Mack R, West S, Kearney BP. Pharmacokinetics of elvitegravir and etravirine following coadministration of ritonavir-boosted elvitegravir and etravirine. Antivir Ther. 2008;13:1011-1017.

33. Scholler-Gyure M, Kakuda TN, Van Solingen-Ristea R, et al. Pharmacokinetic interaction between etravirine and fluconazole or voriconazole in HIV-negative volunteers. In: 49th Interscience Conference on Antimicrobial Agents and Chemotherapy; 2009 Sep 12-15, San Francisco, CA. Abstract A1-1299.

HIV/AIDS - Research and Palliative Care

\section{Publish your work in this journal}

HIV/AIDS - Research and Palliative Care is an international, peerreviewed open-access journal focusing on advances in research in HIV, its clinical progression and management options including antiviral treatment, palliative care and public healthcare policies to control viral spread. The journal welcomes original research, basic science,
34. Brown KC, Paul S, Kashuba AD. Drug interactions with new and investigational antiretrovirals. Clin Pharmacokinet. 2009; 48:211-241.

35. Ruxrungtham K, Pedro RJ, Latiff GH, et al. Impact of reverse transcriptase resistance on the efficacy of TMC125 (etravirine) with two nucleoside reverse transcriptase inhibitors in protease inhibitor-naive, nonnucleoside reverse transcriptase inhibitor-experienced patients: study TMC125-C227. HIV Med. 2008;9:883-896.

36. Yazdanpanah Y, Fagard C, Descamps D, et al. High rate of virologic suppression with raltegravir plus etravirine and darunavir/ritonavir among treatment-experienced patients infected with multidrugresistant HIV: results of the ANRS 139 TRIO trial. Clin Infect Dis. 2009;49:1441-1449.

37. Vingerhoets J, Tambuyzer L, Azijn H, et al. Resistance profile of etravirine: combined analysis of baseline genotypic and phenotypic data from the randomized, controlled Phase III clinical studies. AIDS. 2010;24:503-514.

38. Vingerhoets J, Buelens A, Peeters M, et al. Impact of baseline NNRTI mutations on the virologic response to TMC125 in the Phase III clinical trials DUET-1 and DUET-2. Antivir Ther. 2007;12 Suppl 1:S34.

39. Tambuyzer L, Azijn H, Rimsky LT, et al. Compilation and prevalence of mutations associated with resistance to non-nucleoside reverse transcriptase inhibitors. Antivir Ther. 2009;14:103-109.

40. Coakley E, Chappey C, Benhamida J, et al. Biological and clinical cutoff analysis for etravirine in the PhenoSense HIV assay. Antivir Ther. 2008;13 Suppl 3:A134.

41. Benhamida J, Chappey C, Coakley E, Parkin N. HIV-1 genotype algorithms for prediction of etravirine susceptibility; novel mutations and weighting factors identified through correlations to phenotype. Antivir Ther. 2008;13 Suppl 3:A142.

42. Haddad M, Stawiski E, Benhamida J, Coakley E. Improved genotypic algorithm for predicting etravirine susceptibility: comprehensive list of mutations identified through correlation with matched pPhenotype. In: 17th Conference on Retroviruses and Opportunistic Infections, 2010 Feb 16-19, San Francisco, CA. Abstract 574.

43. Poveda E, de Mendoza C, Pattery T, Gonzalez Mdel M, Villacian J, Soriano V. Phenotypic impact of resistance mutations on etravirine susceptibility in HIV patients with prior failure to nonnucleoside analogues. AIDS. 2008;22:2395-2398.

44. Sluis-Cremer N, Moore K, Radzio J, Sonza S, Tachedjian G. N348I in HIV-1 reverse transcriptase decreases susceptibility to tenofovir and etravirine in combination with other resistance mutations. AIDS. 2010;24:317-319.

45. Konigs C, Feiterna-Sperling C, Esposito S, et al. Pharmacokinetics and dose selection of etravirine in HIV-infected children between 6 and 17 years, inclusive. In: 16th Conference on Retroviruses and Opportunistic Infections; 2009 Feb8-11, Montreal, Canada. Abstract 879.

46. Gebo KA, Martin S, Corbett C, De Smedt G. Impact of TMC125 on hospitalizations and hospital related costs: 24-week findings from pooled DUET trials. In: International AIDS Conference;2008 Aug 3-8, Mexico City, Mexico. Abstract TUPE 0237.

47. Scholler-Gyure M, Kakuda TN, De Smedt G, et al. A pharmacokinetic study of etravirine (TMC125) co-administered with ranitidine and omeprazole in HIV-negative volunteers. Br J Clin Pharmacol. 2008;66:508-516 